\title{
A Primary Study on Linkage Mechanism Between Financial Risks and Fiscal Risks
}

\author{
Liangqing Zhao', a \\ ${ }^{1}$ School of Economics and Management, Shenyang Ligong University, Shenyang 110159, China; \\ azhaoliangqing1611@163.com
}

Keywords: Financial risks, fiscal risks,linkage mechanism.

\begin{abstract}
The finance results from the real economy, it plays an important role in the process of marketing resource allocation. Besides, effective prevention of financial risks is an important foundation for promoting sustainable economic development. This paper begins with the analysis of the formation mechanism of financial risk from the economic principles. In the analysis of the relationship of linkage mechanism between financial risks and fiscal risks, authors started from the fiscal and financial relationship and took China's financial market as an example to study the transformation from financial risk to fiscal risk, transformation from fiscal risk to financial risk and the reasons of mutual transformation between financial risk and fiscal risk. This research can provide a coherent framework for the analysis of financial risks.
\end{abstract}

\section{Introduction}

Since the 1990s, the frequent financial crises in the world along with the consequent huge economic losses and social unrest have caused thse academic circles to pay great attention to financial risks. Finance is generated from the real economy and plays a very important role in the process of marketing resource allocation. Therefore, effective prevention of financial risks is an important basis for promoting sustainable economic development [1]. Numerous researches have shown that the stability of the financial system can promote economic growth and direct funds to more efficient sectors [2,3]. The world financial market is moving towards liberalization and globalization, and new financial instruments come into being, resulting in factors that cause financial risks to increase and become more complex. Besides, the economic crisis caused by the financial crisis catches many governments off guard, impedes economic growth and intensifies international financial market turmoil. Therefore, governments and international organizations attach great importance to and guard against financial risks. Based on this, this paper combs the formation mechanism and the path of financial risks, analyzes the linkage between financial risks and fiscal risks. And taking China's financial market as an example to analyze the reasons of mutual transformation between financial risks and fiscal risks.

\section{Formation Mechanism of Financial Risks}

The exchange of goods through the currency as a medium which originated from the simple exchange of things ensures that the commodity exchange is no longer constrained by time and space. To a large extent, it promotes the development of commodity economy. But in the meanwhile, it also produces a series of risks, making it difficult to complete the process of commodity monetization and burying hidden dangers for the formation of the economic crisis. A variety of financial instruments continue to spring up, not only promoting the exchange of commodities, but also increasing its own trading volume. However, the economic bubble is also generated, forming potential financial risks.

By using the theories of economics to analyze the formation of financial risks, we can find the sources of financial risks mainly in the following aspects [4]: 1) The division of labor refines constantly and the transaction shows a trend of diversification. The nature of financial activities is the transaction. Considering that one party cannot fulfill the contract will inevitably occur during the 
transaction process, the risks of financial activities are inevitable. 2) There are many uncertainties in the environment. There are many uncertainties in financial activities, such as natural factors and social factors, human factors, technical factors and so on. 3) Economic agents have bounded rationality so that their opportunism tendency is serious. The bounded rationality of subjects of financial transactions leads that financial risks are widespread. In addition, the existence of information asymmetry brings about the adverse selection and the moral hazard of financial transactions, which makes opportunism tendencies exist and induces financial risks. 4) Modern currency takes the form of paper money and credit money. In the modern banking system, a large number of financial instruments spring up so that in the process of issuing the credit money, there would be a credit crisis at any time.

\section{Analysis on the Linkage Mechanism of Financial Risks and Fiscal Risks}

In the macro-control, financial and fiscal instruments have a strong correlation between them. However, the use of their capital will also affect each other. The use of financial capital usually impacts the revenue and expenditure of fiscal funds, and the use of fiscal funds will also often affect the balance of bank credit funds.

\subsection{The relationship between fiscal and finance}

In the course of economic development, fiscal and financial roles are irreplaceable. As the two main economic entities regulating the macro-economic development, they need to coordinate in many aspects. However, due to their different functions and division of labor, in practice, there will be conflicts inevitably.

There is a close link between fiscal and finance, mainly in the following aspects: 1) Finance and fiscal are the two main subjects of state regulation of economic development. To achieve the goal of macro-control of economic development, price stability and full employment, fiscal policy and monetary policy need to be coordinated to achieve the consistent ultimate goal. 2) Their carriers are both funds. In the process of playing the role of economic regulation, they are planned as a whole and intertwine as well. In the process of joint action, finance and the fiscal centralize and allocate disposable funds through different means to form the operational mechanism of the financial fund and the bank capital, achieving macroeconomic regulation and control through the monetary fund jointly.

3) Fiscal and finance participate in the distribution of national income collectively and work together to complete the regulation process of income redistribution in order to maintain the currency at a stable level.

However, due to the different functions, it is bound to appear contradictions more or less between fiscal and finance. These contradictions are manifested as follows; 1) The difference in contents of macro - control. In most cases, fiscal is used for the strategic shift in economic structure, while finance is mostly used for the strategic control of economic aggregates. 2) In the macro-control focus, the finance emphasizes on improving the operating efficiency of macro-economy, while fiscal tends to make the macro-economic distribution pattern better. Fiscal collect and use income for free by tax to adjust persons' economic interests. 3) Fiscal and finance are different in the nature of funds. In terms of the fund characteristics, fiscal funds have the features of compulsory collection and free use, while financial funds have the characteristic of paying for collecting and using, which is non-mandatory. 4) The scopes of the roles of fiscal and finance have different priorities. The financial scope is in the public sector. If the market cannot play its role effectively, the government will make use of fiscal means to do an effective complement to the market failure. Financial is mostly in private sector. It can provide a large number of paid funds to maintain rapid economic growth.

The conflicts of fiscal and finance mentioned above determine the need for a reasonable division of labor between them. Fiscal and financial funds need to operate in their own way. In the process of fund allocation, they cannot be confused and their ways of allocation cannot be abused and misused as well. On the basis of clarifying the fiscal and financial functions, the close relationship between them should be noted in the process of economic regulation. So there must be mutual influence and 
infiltration. In this case, once fiscal risks or financial risks appear, they will inevitably interfere with each other's normal operations. If they are coupled with the problem of unclear attribution of the functions, it is prone to cause the linkage of fiscal risks and financial risks. Therefore, whether fiscal risks and financial risks will appear linkage effect has a very close relationship to a country's economic system.

\subsection{The Mutual Transformation of Fiscal Risk and Financial Risk and Its Reasons}

Currently, the global economy is moving to the direction of financialization continuously and the public property of financial products is more and more obvious. China is in a transition period from planned economy to market economy so that the financial system shared a lot of transition costs with China's finance ministry. Therefore, in this process of it, financial risks will inevitably be translated into fiscal risks. The transformation from fiscal risks to financial risks mainly includes the financialization of fiscal revenue risks and the financialization of financial spending risks.

China is still in the economic transition period. A great relationship between fiscal and financial risks is led by the reality of socialism with Chinese characteristics and they always have countless ties.

Firstly, the cost of transition leads to a great link between the fiscal and financial risks. The cost of transition is reflected, in the one hand, to solve the legacy of the old system, on the other hand, to pay for the establishment of a new system. It has been only 30 years since China's reform and opening-up. With the rapid development and progress of the national economy, the direct consequence reflects the characteristics of the transitioning economy, and it is also very obvious in the allocation of funds. Although the majority of fiscal revenue is spent on public basic requirements and the construction of infrastructures, financial funds are used for other efficient industries. Actually, it is common for financial institutions to be responsible for part of fiscal functions. The only reasonable action is to slow down its effectiveness (such as a variety of poverty alleviation and student loans). Policy-based loans have three distinct characteristics: accessibility, compensation and long-term usage. So it will naturally become bad or dead accounts. Then the social security, for example, should be classified as fiscal spending. However, when the amount of unemployment insurance benefits is raised, the government is not opposed to access to funds through bank loans. Conversely, if the state finance is at risk whether in some western developed countries and regions or relatively backward countries, no matter what the triggers are, the various losses caused will be fiscally compensated. Here are a few examples: China's financial sector sold 270 billion special national debts in 1998 to help banks raise funds, and it injected 45 billion US dollars into Bank of China and China Construction Bank in 2004. The Chinese government made nearly $\$ 1.2$ trillion in state investment to stabilize the domestic economy after subprime mortgage crisis in late 2008. These are the objective costs of the transition, which also lead to the relationship of fiscal and financial risks' reciprocal transformation.

Secondly, the uncertainty of government work leads to a strong correlation between financial and fiscal risks. The scope of government work is extremely arbitrary and must be clearly defined. However, such a specification in China requires quite a period of time to complete. At present, the normativity of government functions has reached even surpassed the requirements of the development of market economy at this stage. Open economic development cannot simply rely on the market or government, but the combination between them. Neither of them can play a leading role in economic development. In the process of economic transition in China, effects on the economy cannot be distinguished clearly between government and the market. The government plays a leading and influential role in the economic development, but the work of the government is not clear. It is a serious drag on the rapid development of the economy and increases the fiscal and financial risks. In terms of resource allocation, excessive government interference seriously interferes in the normal impact of the market on economic development, which makes the allocation of resources unreasonable. For instance, the government forces some financial institutions to lend money to certain projects, making it impossible for financial institutions to conduct loan reviews in accordance with the normal procedures. The ambiguity of government work on the one hand has increased the burden of the government and on the other hand has increases the financial and fiscal risks of economic development. 
Thirdly, the dominance of state-owned economy in China's economic development leads to a great relationship between finance and fiscal. China's state-owned funds largely are provided by state-owned banks, and the development of the whole enterprises in our state depends on the fiscal situation. Therefore, the complicated relationships between the government and enterprises, between the government and the banks and between the enterprises and the government are difficult to draw, which directly make the finance and fiscal have a certain link and lead to increasing risks between them.

\section{Summary}

This paper first analyzes the formation mechanism of financial risks by principles of economics. Next it analyzed the relationship between the linkage mechanism of fiscal risks and financial risks from the relationship between fiscal and finance. Taking the Chinese financial market environment as an example, this paper studies the reasons of transformation from financial risks to fiscal risks, from fiscal risks to financial risks, and the mutual transformation between them. Our research can make people deepen the understanding about the policy of preventing financial risks, strengthen the attention to the existing financial rules and strict implementation while providing a coherent framework for the analysis of financial risks.

\section{References}

[1]. Turner, P. (2014). The global long-term interest rate, financial risks and policy choices in EMEs.

[2]. Embrechts, P., Kaufmann, R., \& Patie, P. (2005). Strategic long-term financial risks: Single risk factors. Computational Optimization and Applications, 32(1-2), 61-90.

[3]. Bouchaud, J. P. (1999). Elements for a theory of financial risks. Physica A: Statistical Mechanics and its Applications, 263(1), 415-426.

[4]. Zopounidis, C. (Ed.). (1998). Operational tools in the management of financial risks. Springer Science \& Business Media.

[5]. Zhang, X., \& Sun, T. (2006). China's current real estate cycle and potential financial risks. China \& World Economy, 14(4), 57-74. 